\title{
PATHWAYS OF CARBOHYDRATE FORMATION IN MAN. I. ISOTOPE DISTRIBUTION IN GLUCOSE FROM NONDIABETIC SUBJECTS GIVEN 1-C 14-ACETATE ${ }^{1,2}$
}

\author{
By WALTON W. SHREEVE \\ (From the Medical Department, Brookhaven National Laboratory, Upton, N. Y., and the \\ Radioisotope Unit, Crile Veterans Administration Hospital, Cleveland, Ohio)
}

(Submitted for publication January 28, 1958; accepted March 20, 1958)

A number of studies with tracers in animals have been done to investigate the metabolic pathways by which carbon of fatty acid is converted to carbohydrate. Analysis of distribution of isotope in the carbon positions of glucose (or glycogen) formed in vivo from position-labeled precursors provides insight into the metabolic routes traversed $(2,3)$. Such studies have generally upheld the concept that fatty acids are degraded to two-carbon units, then incorporated into the tricarboxylic acid cycle, from which three-carbon monocarboxylic acids of the glycolytic pathway and finally hexose derivatives are formed. In conformity with this scheme are the findings that fatty acids labeled in the carboxyl or one of the other odd-numbered carbon positions form glucose or glycogen with isotope almost exclusively in the 3 and 4 carbons, while fatty acids labeled in one of the even-numbered carbon atoms introduce isotope primarily and equally into the $1,2,5$, and 6 carbons $(3,4)$.

In order to gather evidence bearing on the utilization of these fundamental intermediary pathways in the human being and to provide data for comparison with pathological states, such as diabetes $(1,5)$, studies of this type have been commenced by the analysis of distribution of radioisotope in blood glucose after the administration of trace amounts of $1-\mathrm{C}^{14}$-acetate to four cancer patients with presumably normal carbohydrate metabolism.

\section{MATERIALS AND METHODS}

Experimental subjects. General data are given in Table I. All the patients had suffered some weight loss with their disease, but were not wasted and were consuming a regular diet prior to the period of fast stated in Table I. Repeated urinalyses were negative for sugar

1 This research was supported by the Atomic Energy Commission.

2 Preliminary findings were presented at the Annual Meeting of the Federated Societies for Experimental Biology, 1956 (1). content and diabetes was absent from the family history in all cases. Liver disease did not exist clinically at the time of study in any case. However, in the case of G. O., one month after study the alkaline phosphatase was found to be elevated to 24 Bodansky units and the serum bilirubin questionably elevated. Liver nodules were palpable before death two months after study. In the case of B. G., autopsy three and one-half months after $\mathrm{C}^{14}$ study showed approximately 10 metastatic nodules varying from 0.2 to $0.5 \mathrm{~cm}$. in diameter in the liver. Liver function tests (cephalin flocculation, thymol turbidity, serum bilirubin) were all negative in the case of F. K.

Tracer compound. 1- $\mathrm{C}^{14}$-acetic acid was prepared from $\mathrm{BaC}^{14} \mathrm{O}_{3}$ by the Grignard reaction and purified by chromatography on a column of Celite for use with Subjects B. G., G. O., and J. H. Commercially produced 1-C ${ }^{14}$-sodium acetate was used for Subject F. K. Degradation of the latter product demonstrated all of the radioactivity to be in the carboxyl carbon.

Subjects B. G., G. O., J. H., and F. K. received 210, 190,190 , and 500 microcuries, respectively, in a single antecubital intravenous injection. The dose of $1-\mathrm{C}^{\mathbf{1 4}}$ acetate was in each case carried in $0.75 \mathrm{mM}$ of total sodium acetate in $10 \mathrm{ml}$. of 0.9 per cent $\mathrm{NaCl}$.

Collection and purification of blood glucose. Between two and two and a quarter hours after injection of labeled acetate, there was withdrawn from the opposite antecubital vein approximately $150 \mathrm{ml}$. of blood from Subjects B. G. and F. K. and ca. $500 \mathrm{ml}$. from G. O. and J. H. Clotting was prevented by using heparinized apparatus. The blood was promptly hemolyzed with five volumes of water and treated with two volumes each of $0.3 \mathrm{~N} \mathrm{Ba}(\mathrm{OH})_{2}$ and 5 per cent $\mathrm{ZnSO}_{4}$. A clear solution was separated by centrifugation and filtration and then passed successively through columns of cation (Duolite ${ }^{\circledR}$ C-3) and anion (Duolite A-4) exchange resins. The deionized eluate was evaporated to dryness in vacuo and the residue used in the various degradations of glucose. Quantitative glucose measurements were done either by reduction of copper (6) or by formation of hydroxymethylfurfural (7).

Degradation of glucose. Carbon number one (C-1) of glucose was isolated as formic acid after the action of $\mathrm{HBr}$ (8). Conversion of glucose to potassium gluconate followed by reaction of the latter with sodium periodate yielded $\mathrm{C}-1$ as $\mathrm{CO}_{2}, \mathrm{C}-6$ as formaldehyde, and $\mathrm{C}-2, \mathrm{C}-3$, C-4, and C-5 together as formic acid (9). Phenylglucosazones were prepared (10) and either combusted totally 
TABLE I

Clinical data on experimental subjects

\begin{tabular}{lcccccc}
\hline Subject & Age & Sex & $\begin{array}{c}\text { Ht. } \\
(\mathrm{cm})\end{array}$ & $\begin{array}{c}\text { Wt. } \\
(\mathrm{Kg.})\end{array}$ & Diagnosis & $\begin{array}{c}\text { Period } \\
\text { of fast } \\
\text { prior } \\
\text { to expt. }\end{array}$ \\
\hline B. G. & 40 & M & 180 & 93 & $\begin{array}{l}\text { Bronchogenic } \\
\text { carcinoma }\end{array}$ & $20 \mathrm{hrs}$ \\
G. O. & 55 & M & 180 & 77 & $\begin{array}{l}\text { Bronchogenic } \\
\text { Carcinoma }\end{array}$ & $15 \mathrm{hrs}$. \\
J. H. & 60 & M & 178 & 66 & $\begin{array}{l}\text { Bronchogenic } \\
\text { carcinoma }\end{array}$ & $24 \mathrm{hrs}$. \\
F. K. & 63 & F & ca. 156 & 58 & $\begin{array}{l}\text { Carcinoma of } \\
\text { the colon }\end{array}$ & $15 \mathrm{hrs}$. \\
\hline
\end{tabular}

to $\mathrm{CO}_{2}$ (11) or converted by action of periodic acid to formic acid (C-4 plus C-5), formaldehyde (C-6) and the bisphenylhydrazone of mesoxaldehyde (C-1, C-2, and C-3) (12).

Glucose was fermented by Lactobacillus casei to lactic acid, which was degraded by $\mathrm{KMnO}_{4}$ to $\mathrm{CO}_{2}$ ( $\mathrm{C}-3$ plus $\mathrm{C}-4)$ and acetaldehyde. The latter was degraded by $\mathrm{NaOH}$ and $\mathrm{I}_{2}$ to formic acid (C-2 plus C-5) and iodoform (C-1 plus C-6) $(13,14)$. Formic acid was oxidized to $\mathrm{CO}_{2}$ by mercuric acetate, and iodoform was converted to $\mathrm{CO}$ by $\mathrm{AgNO}_{8}$, then to $\mathrm{CO}_{2}$ by $\mathrm{H}_{2} \mathrm{SO}_{4}$ and $\mathrm{I}_{2} \mathrm{O}_{5}$ (13-15). Glucose was fermented by Leuconostoc mesenteroides to lactic acid ( $\mathrm{C}-4, \mathrm{C}-5$, and $\mathrm{C}-6)$, ethanol (C-3 and $\mathrm{C}-2)$ and $\mathrm{CO}_{2}(\mathrm{C}-1)(14,16)$. Ethanol was oxidized by $\mathrm{H}_{2} \mathrm{SO}_{4}$ and $\mathrm{K}_{2} \mathrm{Cr}_{2} \mathrm{O}_{7}$ to acetic acid, from which barium acetate was prepared and pyrolyzed to acetone $(9,14)$. Treatment of the latter with $\mathrm{NaOH}$ and $\mathrm{I}_{2}$ yielded $\mathrm{C}-3$ (of glucose) as $\mathrm{CO}_{2}$ and $\mathrm{C}-2$ as iodoform.

Counting techniques. Some organic compounds (phenylglucosazones, bisphenylhydrazones of mesoxaldehyde, and dimedon complexes of formaldehyde) were directly mounted on filter paper and placed beneath the endwindow of a Geiger-Mueller tube for measurement of radioactivity. Most of the samples of $\mathrm{C}^{14} \mathrm{O}_{2}$ were counted in the same way after mounting of $\mathrm{BaCO}_{8}$ (17). In a later stage of this work (Subject F. K.) $\mathrm{C}^{14} \mathrm{O}_{2}$ was measured in the gaseous state by internal proportional counting (18).

\section{RESULTS}

Multiple kinds of degradation of glucose were used with Subjects B. G., G. O., and J. H. because the fermentation with Leuconostoc mesenteroides (which gives each carbon fraction of glucose separately) was not available until work with F. K. The treatment of glucose with $\mathrm{HBr}$ and of phenylglucosazone and potassium gluconate with periodic acid permitted some separation of the carbon fractions which are not obtained in the fermentative method using Lactobacillus casei. These procedures also served as a check on the degradation with $L$. casei.

Employment of fermentative methods of degradation introduces the possibility of spurious findings due to activities of bacterial metabolism which may to a minor extent dilute or randomize carbon fractions of glucose. Randomization was noted with $L$. casei action on glucose-1-C $C^{14}$ (19) and with $L$. mesenteroides action on glucose containing $C^{14}$ in either the 1,2 , or 6 positions $(9,20)$. With the latter organism Katz, Abraham, Hill and Chaikoff (20) found 2 to 5 per cent of the total $\mathrm{C}^{14}$ in carbon positions other than those expected, while Bernstein, Lentz, Malm, Schambye and Wood (9) found 1 per cent or less.

However, bacterial randomization from Positions 1,2, and 6 of glucose does not necessarily imply randomization from Positions 3 and 4 . Convincing evidence of the validity of small percentages of isotope in $1,2,5$, and 6 , relative to those found in 3 and 4 by the fermentation with L. mesenteroides, was presented by Bernstein and co-workers (9), who also measured the $\mathrm{C}^{14}$ content of outer glucose carbon fractions by independent chemical methods. Excellent agreement was found between the fermentation values and those found on degradation of potassium gluconate and oxidation of glucobenzimidazole.

The findings of degradation of glucose for all four subjects of the present study are shown in Table II. Virtually all of the total radioactivity of glucose was found in C-3 and C-4 for Subjects B. G. and F. K., and is most likely true although not rigidly proved in the cases of $G$. O. and J. H. No more than 3.5 per cent of the total glucose $\mathrm{C}^{14}$ was found in any of the other carbon positions. There was apparently no significant difference between the activities of $\mathrm{C}-3$ and $\mathrm{C}-4$ for Subjects G. O. and J. H., whereas C-4 had distinctly higher activity than C-3 for Subject F. $\mathrm{K}$.

In all cases whether by fermentative or chemical methods trace amounts, of the order of 1 to 3 per cent of the total glucose $\mathrm{C}^{14}$, were found in the outer carbons of glucose. For Subjects B. G., G. O., and J. H., the absolute amounts of $\mathrm{C}^{14}$ measured in these carbons were so low that counting error was high (Table II). From them can be deduced, however, a general impression of 
higher activities in $\mathrm{C}-1$ and $\mathrm{C}-2$ than $\mathrm{C}-5$ and C-6. A more conclusive analysis of the pattern of activity in C-1 to C- 6 was possible in the case of F. K. due to the combination of a larger amount of $\mathrm{C}^{14}$, a more efficient counting method, and a method of degradation which yields each carbon position separately. Among the four outer carbons, C-2 was found to have the highest activity with C-1, C-5, and C-6 containing lesser amounts of $\mathrm{C}^{14}$ in that order.

The overall portion of $\mathrm{C}^{14}$ of the carboxyl-labeled acetate which was present in glucose at two hours after injection was calculated on the assumption that there is a body glucose "pool" which has the same concentration as the blood glucose with which it is mixing, and which on the average occupies a hypothetical "space" equivalent to 20 per cent of body weight (21). The values were found to be 1.3 per cent, 1.8 per cent, 1.2 per cent, and 1.7 per cent of the administered dose for Subjects
B. G., G. O., J. H., and F. K., respectively. The above estimate is a minimal one for total $\mathrm{C}^{14}$ converted to glucose, since it does not include that glucose which was formed and then metabolized within two hours or that which was converted to relatively immobile glycogen.

\section{DISCUSSION}

The finding that after injection of $1-\mathrm{C}^{14}$-acetate virtually all radioisotopic carbon of blood glucose was present in C-3 and C-4 is consistent with previous animal studies and suggests that in the "normal" human liver fatty acid carbons are metabolized via the classical routes, i.e., the Krebs tricarboxylic acid (TCA) cycle and the glycolytic pathway, in the process of conversion to carbohydrate. Figure 1 indicates how the isotope would become thus distributed. It can also be seen from Figure 1, however, that if acetic acid were metabo-

TABLE II

$C^{14}$ distribution in blood glucose following I. V. administration of $1-C^{14}$-sodium acetate ( 200 to 500 microcuries in $1.0 \mathrm{mM}$ ) to non-diabetic human subjects

\begin{tabular}{|c|c|c|c|c|c|c|c|c|c|c|c|c|c|c|c|c|c|c|}
\hline Subject & \multicolumn{2}{|c|}{ B. G. } & \multicolumn{8}{|c|}{ G.O. } & \multicolumn{6}{|c|}{ J.H. } & \multicolumn{2}{|c|}{ F. K. } \\
\hline $\begin{array}{l}\text { Method of } \\
\text { glucose }\end{array}$ & \multicolumn{2}{|c|}{ (a) } & \multicolumn{2}{|l|}{ (a) } & \multicolumn{2}{|l|}{ (b) } & \multicolumn{2}{|c|}{ (c) } & \multicolumn{2}{|c|}{ (d) } & \multicolumn{2}{|c|}{ (b) } & \multicolumn{2}{|c|}{ (c) } & \multicolumn{2}{|c|}{ (e) } & \multicolumn{2}{|c|}{ (e) } \\
\hline $\begin{array}{c}\text { Carbon } \\
\text { Fractions }\end{array}$ & s.a. ${ }^{\dagger}$ & $\% \ddagger$ & s.a. & $\%$ & s.a. & $\%$ & s.a. & $\%$ & s.a. & $\%$ & s.a. & $\%$ & s.a. & $\%$ & s.a. & $\%$ & s.a. & $\%$ \\
\hline 3,4 & 300 & 94 & 310 & 96.5 & & & & & & & & & & & & & & \\
\hline 2.5 & 11 & 3.5 & 6.5 & 2 & & & & & & & & & & & & & & \\
\hline 1.6 & 7 & 2.5 & 5.0 & 1.5 & & & & & & & & & & & & & & \\
\hline 1 & & & & & & & 17 & 2.5 & 16 & 2.5 & & & 5.5 & 1 & 4.5 & 1 & 68 & 1.3 \\
\hline 2 & & & & & & & & & & & & & & & 6. & 1.5 & 79 & 1.5 \\
\hline 3 & & & & & & & & & & & & & & & 180 & 47.5 & 1960 & 38 \\
\hline 4 & & & & & & & & & & & & & & & 184 & 48 & 3030 & 58 \\
\hline 5 & & & & & & & & & & & & & & & 3 & $<1$ & 60 & 1.1 \\
\hline 6 & & & & & 3.5 & $<1$ & 3.5 & $<1$ & & & 2.5 & $<1$ & 2.5 & $<1$ & 3 & $<1$ & 42 & .8 \\
\hline $1-6$ & & & & & 110 & 100 & & & & & 77 & 100 & & & & & & \\
\hline $1-3$ & & & & & 99 & 45 & & & & & 74 & 48.5 & & & & & & \\
\hline 4,5 & & & & & 162 & 49 & & & & & 104 & 50 & & & & & & \\
\hline $2-5$ & & & & & & & 164 & 97 & & & & & 106 & 98 & & & & \\
\hline
\end{tabular}

* (a) fermentation with Lactobacillus casei, etc.

(b) formation and oxidation of phenylglucosazone, etc.

(c) formation and oxidation of potassium gluconate, etc.

(d) oxidation with hydrogen bromide, etc.

(e) fermentation with Leuconostoc mesenteroides, etc.

$\dagger$ specific activity $=$ counts $/$ minute $/$ milligram carbon: for s.a. values above $50, S . D$. of sampling and counting $=< \pm 5 \%$; for s.a. values from 20 to 50, S. D. $= \pm 5$ to $10 \%$; for s.a. values below $20, S . D$. $= \pm 5$ to $35 \%$; where $S . D$. (stand. dev.) $=$ $\sqrt{\sum d^{2}}$

$\$$ per cent of total glucose $C^{14}$ contained in given carbon fractions. 


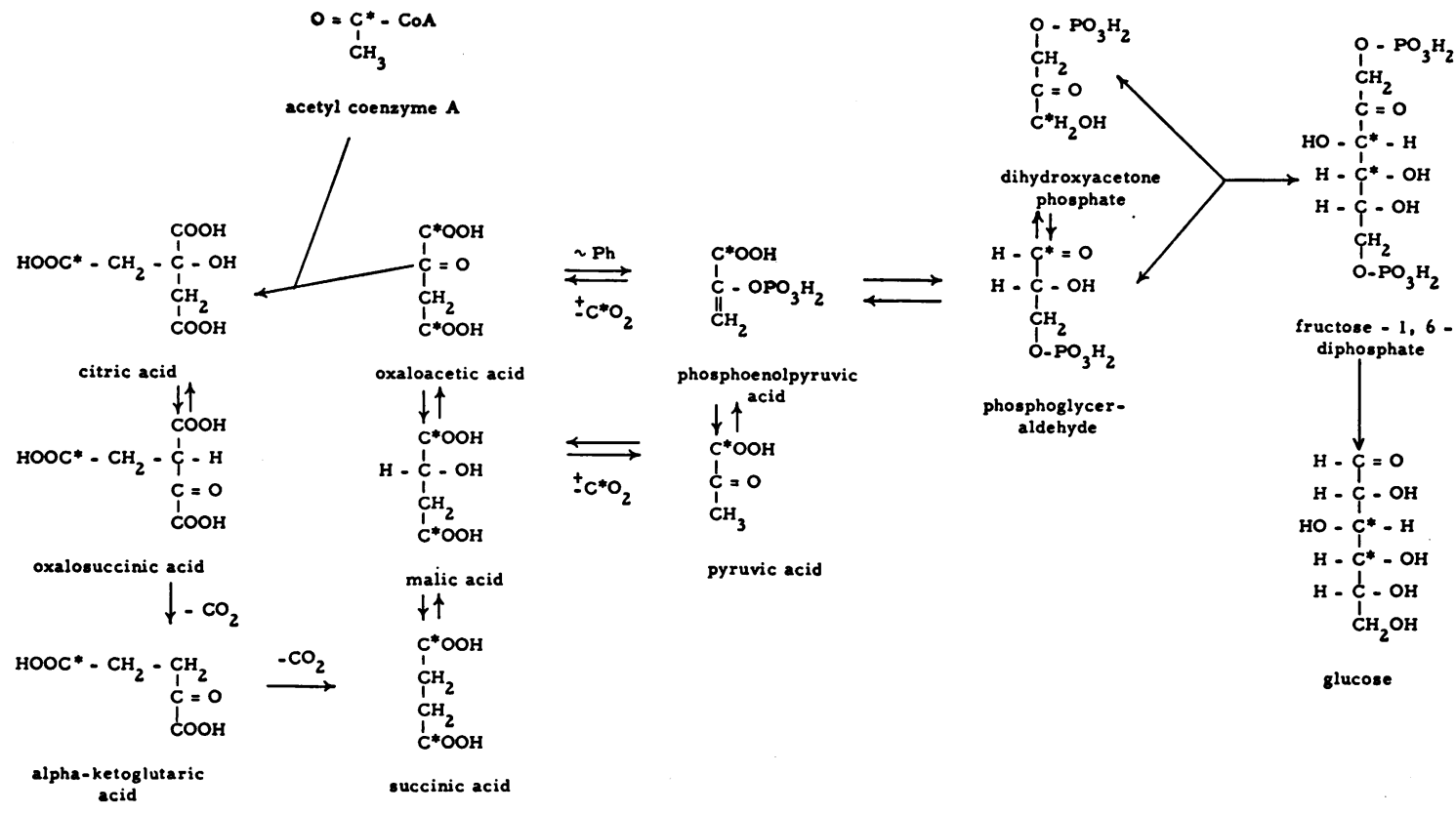

Fig. 1. Abbreviated Tricarboxylic Acto Cycle and Glycolytic Reactions Asterisks indicate location of $\mathrm{C}^{14}$.

lized to $\mathrm{CO}_{2}$ by some other pathway and then fixed into dicarboxylic acids, the distribution of $\mathrm{C}^{14}$ in glucose would be the same. It is fundamental to recognize that the net carbon balance in the process of $\mathrm{C}^{14}$ introduction from acetate into glucose is zero whether by way of the TCA cycle or by $\mathrm{CO}_{2}$ fixation, and that there can therefore by these pathways be no true gluconeogenesis from the two-carbon fragments of fat catabolism.

Of interest is the observation that for two subjects (J. H. and G. O.) the $\mathrm{C}^{\mathbf{1 4}}$ activity in C-3 was not essentially different than that in C-4, whereas for another subject (F. K.) activity in C-4 was approximately 50 per cent higher than in C-3. Similar variations in symmetry of glucose labeling have been observed by other workers using 2-C ${ }^{14}$-pyruvate (22) and $\mathrm{C}^{14} \mathrm{O}_{2}$ (23) in rats, where the asymmetry appeared to depend upon recent provision of food or unlabeled substrate. Findings from these studies, together with the complementary finding of more $\mathrm{C}^{14}$ in C-3 than in C-4 of glycogen glucose after administration of 1-C ${ }^{14}$-glycerol. (24), have led to the hypothesis that unequal labeling between $\mathrm{C}-3$ and C-4 occurs as a result of incomplete equilibration between dihydroxyacetone phosphate and phosphoglyceraldehyde in the presence of appreciable amounts of one or the other unlabeled trioses. Another interpretation has been offered with the demonstration of an exchange of phosphoglyceraldehyde with fructose-di-phosphate by means of a complex between dihydroxyacetone phosphate and aldolase (25). It might also be considered that by operation of various transketolations and transaldolations (26) the first 3 carbons of glucose may undergo rearrangements not shared by the 4, 5, and 6 carbons, and that lack of symmetry could result therefrom.

Further interest attaches to the presence of trace amounts of $\mathrm{C}^{14}$ in the $1,2,5$, and 6 carbons because it is indicative of metabolic reactions not encompassed in the TCA cycle and the glycolytic scheme. Early observations suggested trace activity in the outer carbons of glycogen glucose after administration of carboxyl-labeled fatty acid (3) or of radioactive bicarbonate (27). More recent and definitive studies $(9,23,28)$ have indicated the presence of a small amount of activity ( 5 per cent or less of the glucose $\mathrm{C}^{14}$ ) in each of the outer carbons of glucose from rat liver glycogen after formation from $\mathrm{NaHC}^{14} \mathrm{O}_{3}$. There has generally been observed more in $\mathrm{C}-1$ and $\mathrm{C}-2$ than C-5 and C-6.

The oxidative route for glucose metabolism 
with reformation of hexose via the pentose phosphate cycle has been discussed by Wood (29) and Racker (26) among others as a means of extension of tracer, primarily to C-2, from originally 3,4-labeled glucose. Further extension to Positions 1,5 , and 6 may take place by recycling in the glucose oxidative pathway and by conversion of hexose to triose with subsequent $\mathrm{CO}_{2}$ fixation and randomization in the Krebs cycle. Additionally, extension from $\mathrm{C}-3$ to both of the first 2 carbons of glucose may take place by reactions of transketolation and transaldolation operating reversibly and separately from the complete oxidative cycle for glucose (thus accounting for activity in C-1 similar to that in C-2 and higher than in C-5 and C-6).

Other mechanisms, such as $\mathrm{CO}_{2}$ fixation with pentose phosphate (labeling $\mathrm{C}-1$ of hexose), are possible but less likely $(23,30)$, as would presumably be the recently-elucidated glucuronic acidxylulose pathway (31), which would transfer carbon from C-4 to C-5 of hexose. Still other reactions, which would label the outer carbons along with net formation of glucose from $1-\mathrm{C}^{14}$-acetate, are mentioned in a subsequent paper (5). The findings from the present study of traces of $\mathrm{C}^{\mathbf{1 4}}$ in the outer carbon of glucose would seem primarily to suggest the operation in the human liver of the oxidative and the nonoxidative reactions of the pentose phosphate cycle. The low level of activity of these reactions relative to the rate of glucose synthesis via the Embden-Meyerhof pathway appears to be about the same as that found for normal rat $(9,23,27)$ and mouse (29) liver. It may be noted that in glycogen from rabbit liver slices incubated with $\mathrm{NaHC}^{14} \mathrm{O}_{3}$, Topper and Hastings (12) found no $\mathrm{C}^{14}$ in positions other than 3 and 4, nor did Abraham, Chaikoff and Hassid (32) after injecting 1-C $\mathrm{C}^{\mathbf{1 4}}$-tripalmitin into diabetic dogs and analyzing urinary glucose.

The overall fraction (average of 1.5 per cent) of the administered $\mathrm{C}^{14}$ found in the theoretical "pool" of miscible body glucose at two hours is of the same general order of magnitude as that calculated by Strisower, Chaikoff and Weinman (10) for extracellular glucose of the rat at one hour after injection of 6 -C ${ }^{14}$-tripalmitin ( 0.6 per cent for normal and 2.3 per cent for diabetic) as well as that found by Abraham and co-workers (32) to be excreted in the urine by the diabetic dog within 24 hours after injection of $1-C^{14}$-tripalmitin (4.7 per cent). Unfortunately, there are no available data for the human on the amount to be expected simply from $\mathrm{C}^{14} \mathrm{O}_{2}$ fixation, so it cannot in this way be determined whether an additional amount of $\mathrm{C}^{14}$ was incorporated from acetate via particular pathways such as the tricarboxylic acid cycle.

At the time this investigation was initiated it was deemed necessary to use cancer patients as subjects representative of the "normal" and nondiabetic human in order to be able to use sufficient amounts of $\mathrm{C}^{14}$. It has recently been emphasized $(21,33)$ that some patients with cancer tend to have an alteration of carbohydrate metabolism in the direction of the diabetic type. Whether this situation has had any influence on the present findings cannot be stated. However, the subjects were manifestly not in the acute diabetic state of patients with whom they have been compared (5). In another way the presence of a neoplasm (ascites cell tumor of mice) has been shown to change the pattern of labeling of liver glycogen, but not appreciably unless the tumor cells have first access to the labeled precursor as a result of its intraperitoneal injection (34). It can indeed be questioned generally whether the pattern of label in blood glucose from the intact organism reflects only hepatic metabolism, since some other organ or tissue may have taken part in distribution of the isotope either before or after the formation of glucose in the liver or by extra-hepatic (e.g., renal) gluconeogenesis. It may be noted in this connection that intermediates of the pentose phosphate cycle have been found to occur in human hemolysates (35).

\section{SUM MARY}

The nature of various metabolic pathways used in the transfer of carbon from fatty acid to carbohydrate in the human being has been investigated by means of $\mathrm{C}^{\mathbf{1 4}}$ tracing. The experimental subjects were four patients with carcinoma (of the lung or colon) who had no grossly evident abnormality in carbohydrate metabolism. They were fasted for 15 to 24 hours prior to the test. Single intravenous injections of trace amounts of carboxyl-labeled sodium acetate (200 to 500 microcuries) were followed two hours later by collec- 
tion of blood from which glucose was isolated and subsequently degraded to individual or groups of carbon fractions by various bacteriological and chemical methods.

As in previous similar studies with animals, virtually all of the radioisotopic carbon of glucose was present in the 3 and 4 positions of the molecule. Whereas in two patients the activity of these two positions was essentially equal, in one patient there was more activity in C-4 than C-3. In each of the other positions $(1,2,5$, and 6$)$ there was a slight amount of radioactivity, of the order of 1 to 2 per cent of the total glucose $\mathrm{C}^{14}$ in each position. There appeared to be generally more in C-1 and C-2 than C-5 and C-6. An average of 1.5 per cent of the administered $\mathrm{C}^{14}$ was estimated to be present in free body glucose at the time of sampling.

The finding of primarily 3,4-labeled glucose is consistent with the operation of the tricarboxylic acid cycle and the glycolytic pathway as the principal routes for passage of carbon from fatty acid to carbohydrate. The presence and relative amounts of tracer in the $1,2,5$, and 6 carbons suggest the operation of reactions of the pentose phosphate cycle.

\section{ACKNOWLEDGMENTS}

The author is indebted to Mrs. Genevieve E. Incefy and Mrs. Elizabeth M. Jellett for able technical assistance, and to Drs. H. G. Wood, I. A. Bernstein, P. A. Marks, and D. D. Van Slyke for helpful advice in the preparation of this manuscript. He wishes to thank Dr. Daniel Laszlo and Dr. Herta Spencer of Montefiore Hospital in New York for cooperation in the study of Subject F. K.

\section{REFERENCES}

1. Shreeve, W. W. Glucogenesis from 1-C $\mathrm{C}^{14}$-acetate in non-diabetic and diabetic man. Fed. Proc. 1956, 15, 354.

2. Wood, H. G. The synthesis of liver glycogen in the rat as an indicator of intermediary metabolism. Cold Spr. Harb. Sym. quant. Biol. 1948, 13, 201.

3. Chaikoff, I. L., and Brown, G. W., Jr. Fat metabolism and acetoacetate formation in Chemical Pathways of Metabolism, D. M. Greenberg, Ed. New York, Academic Press Inc., 1954, vol. 1, p. 277.

4. Lifson, N., Lorber, V., Sakami, W., and Wood, H. G. The incorporation of acetate and butyrate carbon into rat liver glycogen by pathways other than carbon dioxide fixation. J. biol. Chem. 1948, 176, 1263.
5. Shreeve, W. W., and Hennes, A. R. Pathways of carbohydrate formation in man. II. The effect of diabetes and glucocorticoid administration on isotope distribution in glucose from subjects given 1-C $\mathrm{C}^{14}$-acetate. J. clin. Invest. 1958, 37, 1006.

6. Somogyi, M. A new reagent for the determination of sugars. J. biol. Chem. 1945, 160, 61.

7. Mendel, B., Kemp, A., and Myers, D. K. A colorimetric micro-method for the determination of glucose. Biochem. J. 1954, 56, 639.

8. Sowden, J. C. The action of hydrobromic acid on 1-C16-D-glucose. J. Amer. chem. Soc. 1949, 71, 3568.

9. Bernstein, I. A., Lentz, K., Malm, M., Schambye, P., and Wood, H. G. Degradation of glucose-C ${ }^{14}$ with Leuconostoc mesenteroides; alternate pathways and tracer patterns. J. biol. Chem. 1955, 215, 137.

10. Strisower, E. H., Chaikoff, I. L., and Weinman, E. O. Conversion of $\mathrm{C}^{\mathbf{1 4}}$-palmitic acid to glucose. I. Normal and diabetic rats. J. biol. Chem. 1951, 192, 453.

11. Van Slyke, D. D., and Folch, J. Manometric carbon determination. J. biol. Chem. 1940, 136, 509.

12. Topper, Y. J., and Hastings, A. B. A study of the chemical origins of glycogen by use of $C^{16}$-labeled carbon dioxide, acetate, and pyruvate. J. biol. Chem. 1949, 179, 1255.

13. Wood, H. G., Lifson, N., and Lorber, V. The position of fixed carbon in glucose from rat liver glycogen. J. biol. Chem. 1945, 159, 475.

14. Bernstein, I. A., and Wood, H. G. Determination of isotopic carbon patterns in carbohydrate by bacterial fermentation in Methods in Enzymology, S. P. Colowick and N. O. Kaplan, Eds. New York, Academic Press Inc., 1957, vol. IV, p. 561.

15. Shreeve, W. W., Leaver, F., and Siegel, I. A method for the specific conversion of iodoform to carbon dioxide. J. Amer. chem. Soc. 1952, 74, 2404.

16. Gunsalus, I. C., and Gibbs, M. The heterolactic fermentation. II. Position of $\mathrm{C}^{14}$ in the products of glucose dissimilation by Leuconostoc mesenteroides. J. biol. Chem. 1952, 194, 871.

17. Henriques, F. C., Jr., Kistiakowsky, G. B., Margnetti, C., and Schneider, W. G. Analytical procedure for measurement of long-lived radioactive sulfur, $\mathrm{S}^{25}$, with a Lauritzen electroscope and comparison of electroscope with special Geiger counter. Industr. Engin. Chem. 1946, 18, 349.

18. Van Slyke, D. D., Steele, R., and Plazin, J. Determination of total carbon and its radioactivity. J. biol. Chem. 1951, 192, 769.

19. Gibbs, M., Dumrose, R., Bennett, F. A., and Bubeck, M. R. On the mechanism of bacterial fermentation of glucose to lactic acid studied with $\mathrm{C}^{16}$ glucose. J. biol. Chem. 1950, 184, 545.

20. Katz, J., Abraham, S., Hill, R., and Chaikoff, I. L. The occurrence and mechanism of the hexose monophosphate shunt in rat liver slices. J. biol. Chem. 1955, 214, 853. 
21. Marks, P. A., and Bishop, J. S. The glucose metabolism of patients with malignant disease and of normal subjects as studied by means of an intravenous glucose tolerance test. J. clin. Invest. 1957, 36, 254.

22. Landau, B. R., Hastings, A. B., and Nesbett, F. B. Origin of glucose and glycogen carbons formed from $\mathrm{C}^{14}$-labeled pyruvate by livers of normal and diabetic rats. J. biol. Chem. 1955, 214, 525.

23. Marks, P. A., and Horecker, B. L. Distribution of radioactive carbon dioxide incorporated into rat liver glycogen. J. biol. Chem. 1956, 218, 327.

24. Schambye, P., Wood, H. G., and Popják, G. Biological asymmetry of glycerol and formation of asymmetrically labeled glucose. J. biol. Chem. 1954, 206, 875.

25. Rose, I. A. The mechanism of action of aldolase and the asymmetric labeling of hexose. Proc. nat. Acad. Sci. (Wash.) 1958, 44, 10.

26. Racker, E. Micro- and macrocycles in carbohydrate metabolism. Harvey Lect. 1957, 51, 143.

27. Shreeve, W. W., Feil, G. H., Lorber, V., and Wood, H. G. The distribution of fixed radioactive carbon in glucose from rat liver glycogen. J. biol. Chem. 1949, 177, 679.
28. Marks, P. A., and Feigelson, P. The biosynthesis of nucleic acid ribose and of glycogen glucose in the rat. J. biol. Chem. 1957, 226, 1001.

29. Wood, H. G. Significance of alternate pathways in the metabolism of glucose. Physiol. Rev. 1955, 35, 841.

30. Hiatt, H. H. Glycogen formation via the pentose phosphate pathway in mice in vivo. J. biol. Chem. 1957, 224, 851.

31. McCormick, D. B., and Touster, O. The conversion in vivo of xylitol to glycogen via the pentose phosphate pathway. J. biol. Chem. 1957, 229, 451.

32. Abraham, S., Chaikoff, I. L., and Hassid, W. Z. Conversion of $\mathrm{C}^{\mathbf{1 6}}$-palmitic acid to glucose. II. Specific glucose carbons labeled. J. biol. Chem. 1952, 195, 567.

33. Glicksman, A. S., and Rawson, R. W. Diabetes and altered carbohydrate metabolism in patients with cancer. Cancer 1956, 9, 1127.

34. Hiatt, H. H. Glycolytic activity in vivo of the mouse Ehrlich ascites tumor. Cancer Res. 1957, 17, 240.

35. Dische, $Z$. Equilibrium between glucose- and fructose-6-phosphate and sedoheptulose phosphate, triose phosphate, and pentose phosphate in human hemolysates. Fed. Proc. 1957, 16, 173. 